\title{
Theoretical insight into the roles of cocatalysts in the Ni-NiO/ $\beta$ - Ga2O3 photocatalyst for overall water splitting
}

\section{Citation for published version (APA):}

Liu, T., Tranca, I. C., Yang, J., Zhou, X., \& Li, C. (2015). Theoretical insight into the roles of cocatalysts in the Ni$\mathrm{NiO} / \beta-\mathrm{Ga}_{2} \mathrm{O}_{3}$ photocatalyst for overall water splitting. Journal of Materials Chemistry A, 3(19), 10309-10319.

https://doi.org/10.1039/C5TA02193F

\section{Document license: \\ TAVERNE}

DOI:

10.1039/C5TA02193F

Document status and date:

Published: 21/05/2015

\section{Document Version:}

Publisher's PDF, also known as Version of Record (includes final page, issue and volume numbers)

\section{Please check the document version of this publication:}

- A submitted manuscript is the version of the article upon submission and before peer-review. There can be important differences between the submitted version and the official published version of record. People interested in the research are advised to contact the author for the final version of the publication, or visit the $\mathrm{DOI}$ to the publisher's website.

- The final author version and the galley proof are versions of the publication after peer review.

- The final published version features the final layout of the paper including the volume, issue and page numbers.

Link to publication

\section{General rights}

Copyright and moral rights for the publications made accessible in the public portal are retained by the authors and/or other copyright owners and it is a condition of accessing publications that users recognise and abide by the legal requirements associated with these rights.

- Users may download and print one copy of any publication from the public portal for the purpose of private study or research.

- You may not further distribute the material or use it for any profit-making activity or commercial gain

- You may freely distribute the URL identifying the publication in the public portal.

If the publication is distributed under the terms of Article 25fa of the Dutch Copyright Act, indicated by the "Taverne" license above, please follow below link for the End User Agreement:

www.tue.nl/taverne

Take down policy

If you believe that this document breaches copyright please contact us at:

openaccess@tue.nl

providing details and we will investigate your claim. 


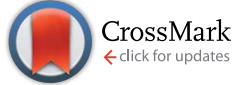

Cite this: J. Mater. Chem. A, 2015, 3, 10309

Received 26th March 2015 Accepted 10th April 2015

DOI: $10.1039 / c 5 t a 02193 f$

www.rsc.org/MaterialsA

\section{Theoretical insight into the roles of cocatalysts in the $\mathrm{Ni}-\mathrm{NiO} / \beta-\mathrm{Ga}_{2} \mathrm{O}_{3}$ photocatalyst for overall water splitting $\dagger$}

\begin{abstract}
Taifeng Liu, ${ }^{\text {ab }}$ Ionut Tranca, ${ }^{c}$ Jingxiu Yang, ${ }^{\text {ab }}$ Xin Zhou*a and Can Li ${ }^{\star a}$
The formation and stability of $\mathrm{Ni}_{n}$ and $(\mathrm{NiO})_{n}(n=1-4)$ clusters on the $\beta-\mathrm{Ga}_{2} \mathrm{O}_{3}$ surface have been studied by means of first-principles density functional theory calculations. It is found that the optimum interaction of the $\mathrm{Ni}_{n}$ and $(\mathrm{NiO})_{n}$ clusters with the surface requires different surface sites. This optimizes the formation of interfacial bonds between the atoms from clusters and the coordinatively unsaturated atoms from the surface. The stability of the adsorbed Ni clusters increases with the number of $\mathrm{Ni}$ atoms. In a $\mathrm{Ni}_{n} / \mathrm{Ga}_{2} \mathrm{O}_{3}$ system, as the Ga unoccupied states overlap with the unoccupied $\mathrm{Ni}$ state, the excited electrons transferred from $\mathrm{Ga}$ to $\mathrm{Ni}$ participate in the proton reduction reaction. Our calculations show that $(\mathrm{NiO})_{n}$ clusters strongly adsorb on the $\mathrm{Ga}_{2} \mathrm{O}_{3}$ surface due to the negative adsorption energies within $-1.9 \mathrm{eV}$ to $-3.7 \mathrm{eV}$. For $(\mathrm{NiO})_{n} / \mathrm{Ga}_{2} \mathrm{O}_{3}$, occupied states from the $(\mathrm{NiO})_{n}$ cluster may accept the holes from $\mathrm{O}$ atoms in the $\mathrm{Ga}_{2} \mathrm{O}_{3}$ surface to take part in the photocatalytic water oxidation reaction.
\end{abstract}

\section{Introduction}

Photocatalytic overall splitting of water over semiconductors has drawn great attention as one of the possible strategies for environmental remediation and energy conversion. ${ }^{1-5}$ Generally, a heterogeneous photocatalytic system is composed of a semiconductor and cocatalysts. ${ }^{6}$ The semiconductor is responsible for harvesting light, while photocatalytic reactions take place on cocatalysts loaded on the semiconductor. Cocatalysts can not only serve as reaction sites and catalyze reactions, but also promote the charge separation and transport driven by junctions/interfaces formed between the cocatalyst and light harvesting semiconductor. ${ }^{7}$ Many research studies show that loading suitable cocatalysts can significantly increase the photocatalytic activities of hydrogen and oxygen evolution reactions. ${ }^{8-12}$ Typically, the cocatalyst is a noble metal for reduction reactions (such as $\mathrm{Pt}, \mathrm{Pd}, \mathrm{Ru}, \mathrm{Rh}$ and $\mathrm{Au}$ ) or transition-metal oxide for oxidation reactions (such as $\mathrm{CoO}_{x}, \mathrm{NiO}_{x}, \mathrm{IrO}_{2}, \mathrm{MnO}_{x}$ and $\mathrm{RuO}_{2}$ ).

Nickel oxide has often been employed in many photocatalytic systems for water splitting, ${ }^{3}$ such as $\mathrm{Ga}_{2} \mathrm{O}_{3},{ }^{13,14}$ $\mathrm{SrTiO}_{3},{ }^{15-17} \mathrm{La}: \mathrm{KTaO}_{3},{ }^{18} \mathrm{~K}_{4} \mathrm{Nb}_{6} \mathrm{O}_{17},{ }^{19}$ and $\mathrm{Ba}_{5} \mathrm{Nb}_{4} \mathrm{O}_{15} \cdot{ }^{20}$ In

\footnotetext{
${ }^{a}$ State Key Laboratory of Catalysis, Dalian Institute of Chemical Physics, Chinese Academy of Sciences, Dalian National Laboratory for Clean Energy, Dalian 116023, China.E-mail:xzhou@dicp.ac.cn; canli@dicp.ac.cn

${ }^{b}$ Graduate University of Chinese Academy of Sciences, Beijing 100049, China ${ }^{c}$ Schuit Institute of Catalysis, Laboratory of Inorganic Materials Chemistry, Eindhoven University of Technology, Den Dolech 2, 5612 AZ Eindhoven, The Netherlands

$\uparrow$ Electronic supplementary information (ESI) available. See DOI: $10.1039 / \mathrm{c} 5 \mathrm{ta} 02193 \mathrm{f}$
}

general, the pretreatment of $\mathrm{H}_{2}$ reduction and subsequent $\mathrm{O}_{2}$ oxidation is indispensable for nickel oxide loaded photocatalysts to show high activities. So the pretreated nickel oxide cocatalyst is often denoted as $\mathrm{NiO}_{x}$ in the literature. ${ }^{13-20} \mathrm{Ga}_{2} \mathrm{O}_{3}$, as a representative of semiconductors with a $\mathrm{d}^{10}$ electronic configuration, exhibits high photocatalytic activity for water splitting. ${ }^{13,14}$ The results reported by Yanagida et al. show that only $\mathrm{H}_{2}$ production was observed when $\mathrm{Ga}_{2} \mathrm{O}_{3}$ was used as the photocatalyst without $\mathrm{NiO}_{x}$ loading, and the activity was relatively low. ${ }^{13}$ A recent study showed that $\mathrm{NiO}_{x}$ loading is necessary to induce the stoichiometric formation of $\mathrm{H}_{2}$ and $\mathrm{O}_{2}$ by photocatalytic decomposition of water on $\mathrm{Ga}_{2} \mathrm{O}_{3}$ with tunable $\alpha-\beta$ phase junctions. ${ }^{\mathbf{1 4}}$

Cocatalysts are typically present as nanoparticles on the semiconductor surface loaded by impregnation or in situ photodeposition. ${ }^{21}$ The structural complexity of the nano-sized metal or metal oxide clusters on semiconductor surfaces makes it difficult to obtain structural and electronic information of these systems even under well-defined experimental conditions. Theoretical studies based on first-principles electronic structure calculations have proven to be useful for complementing the experimental results to illuminate the relationship between the surface structure and the physical and chemical properties of semiconductors, and further to understand the mechanism of the photocatalytic reaction..$^{22-30}$

Although experimental observations indicate that cocatalysts play an important role in promoting charge separation and increasing activity in photocatalytic systems, several critical questions on cocatalysts are still open. For example, how and where does a cocatalyst locate on the surface of semiconductors? How does the adsorption of the cocatalyst affect 
the electronic properties of photocatalysts? Why does loading cocatalysts promote the charge separation? To answer these questions, we took the $\mathrm{Ni}-\mathrm{NiO} / \beta-\mathrm{Ga}_{2} \mathrm{O}_{3}$ photocatalytic system as a model and performed detailed theoretical calculations. In the present work, we computed the surface structures and formation energies of five different surfaces of $\beta-\mathrm{Ga}_{2} \mathrm{O}_{3}$, determined the stable configurations of $\mathrm{Ni}_{n}$ and $(\mathrm{NiO})_{n}(n=1-4)$ clusters adsorbed on the most stable surface of $\beta-\mathrm{Ga}_{2} \mathrm{O}_{3}$, and investigated the electronic properties and charge distribution for these systems. We found that small $\mathrm{Ni}_{n}$ and $(\mathrm{NiO})_{n}$ clusters tend to form on different sites of the surface. The electronic structure analyses indicate that $\mathrm{Ni}_{n} / \mathrm{Ga}_{2} \mathrm{O}_{3}$ systems participate in the photocatalytic hydrogen evolution reaction (HER) while (NiO) $)_{n} /$ $\mathrm{Ga}_{2} \mathrm{O}_{3}$ systems tend to take part in the photocatalytic oxygen evolution reaction (OER).

\section{Computational details}

All the DFT spin-polarized calculations were performed with the VASP (Vienna Ab initio Simulation Package) code. ${ }^{31,32}$ The exchange-correlation potential was described through the Perdew-Burke-Ernzerhof (PBE) functional within the generalized gradient approximation formalism. ${ }^{33}$ The projector-augmented wave method was applied to describe electron-ion interactions. ${ }^{34,35}$ A Hubbard $U$ term acting on the Ni 3d orbitals was added to the standard PBE functional employing the rotationally invariant formalism developed by Dudarev et al. ${ }^{36}$ in which only the difference $\left(U_{\text {eff }}=U-J\right)$ between the Coulomb $U$ and exchange $J$ parameters is considered. In the present work, a value of $U_{\text {eff }}=5.3 \mathrm{eV}$ was used, which was calculated selfconsistently by Ferrari et al. ${ }^{37}$ and which is in the range of $5-6 \mathrm{eV}$ interval found in the literature. ${ }^{36,38,39}$
Among the five different crystalline structures of $\mathrm{Ga}_{2} \mathrm{O}_{3}, \beta$ $\mathrm{Ga}_{2} \mathrm{O}_{3}$ is the most stable crystal phase. ${ }^{40}$ This crystal phase exhibits excellent photocatalytic activity, ${ }^{\mathbf{4 1 , 4 2}}$ and it is the subject of extensive experimental and theoretical studies. ${ }^{4-49}$ So in this work, we chose $\beta-\mathrm{Ga}_{2} \mathrm{O}_{3}$ to represent the semiconductor in photocatalytic systems. Full optimization of the cell parameters for the bulk $\beta-\mathrm{Ga}_{2} \mathrm{O}_{3}$ with a monoclinic structure (Fig. 1(a)) was carried out by using the $3 \times 11 \times 7$ Monkhorst-Pack type $k$ point sampling. The cutoff energy for the plane wave basis set was fixed at $520 \mathrm{eV}$. The calculated lattice parameters, $a=$ $12.504 \AA$, $b=3.101 \AA$, $c=5.915 \AA$, and $\beta=103.71^{\circ}$, are in good agreement with the experimental data. ${ }^{50}$ For all the surface calculations a vacuum layer of $15 \AA$ was used in order to avoid the interaction between periodic slabs. For the calculation of the surface energy, $(1 \times 1)$ cells were considered, a MonkhorstPack set of $3 \times 3 \times 1 k$-points was applied and all the atomic layers in the slabs were allowed to relax. During the optimization of the surfaces covered with adsorbates, a $(3 \times 2)$ supercell including a cell composition $\left(\mathrm{Ga}_{2} \mathrm{O}_{3}\right)_{24}$ was used. The upper half of the slab and the adsorbates were allowed to relax, while the bottom half of the slab was fixed at its optimized bulk position. Dipolar corrections were included along the axis normal to the surface. The geometries were considered to be converged when the forces on each ion were less than $0.01 \mathrm{eV} \AA^{-1}$.

On top of the optimized geometries obtained at the GGA-PBE level, a more accurate approach, the hybrid HSE06 functional, ${ }^{51-53}$ was used to calculate the electronic properties for the most stable structures. This is necessary in order to achieve a good agreement between the experimental and the theoretical band gaps. The HSE06 functional includes a fraction $\alpha$, of screened, short-range HF exchange to improve the derivative discontinuity of the Kohn-Sham potential for integer electron numbers. The percentage of HF exchange in a hybrid functional

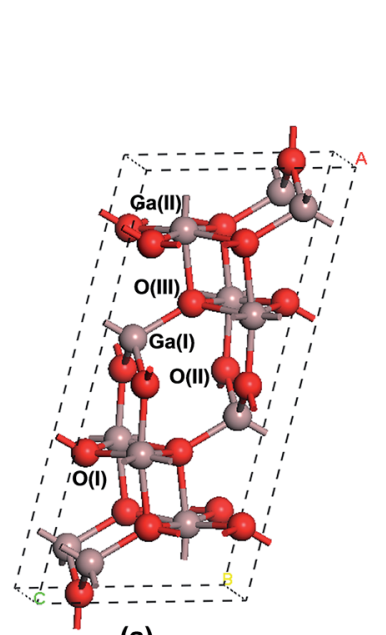

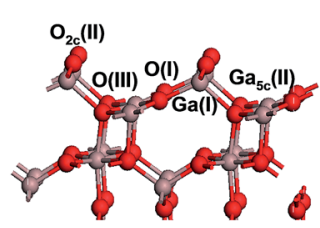

(b)

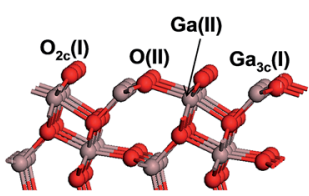

(d)

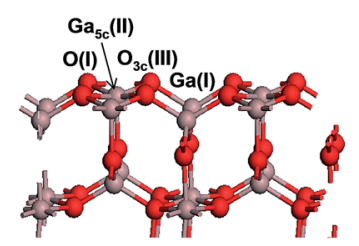

(c)

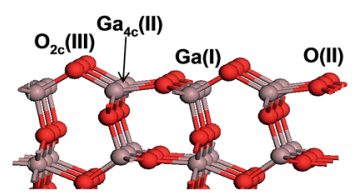

(e)

(a)

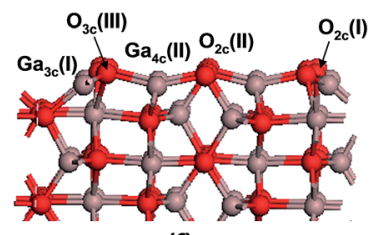

(f)

Fig. 1 Illustration of bulk $\beta-\mathrm{Ga}_{2} \mathrm{O}_{3}$ crystal and stoichiometric surfaces: (a) bulk, (b) (100)-A, (c) (100)-B, (d) (001)-A, (e) (001)- $B$, and (f) (010). The red and brown balls stand for oxygen and gallium, respectively. 
is not a universal constant and the optimal value can be systemdependent. The band gap of bulk $\beta-\mathrm{Ga}_{2} \mathrm{O}_{3}$ obtained from experiments was found to be in the range of 4.2-4.7 $\mathrm{eV}^{\mathbf{1 4 , 3 3 , 5 4 , 5 5}}$ In the present work, $\alpha=0.3$ was used as this value can yield good agreement between the computed band gap (4.5 eV) and the experimental results.

\section{Results and discussion}

\subsection{Bulk and surface properties}

Fig. 1(a) shows that the unit cell of $\beta-\mathrm{Ga}_{2} \mathrm{O}_{3}$ contains four $\mathrm{Ga}_{2} \mathrm{O}_{3}$ formula units with two nonequivalent $\mathrm{Ga}$ sites and three nonequivalent $\mathrm{O}$ sites. $\mathrm{Ga}(\mathrm{I})$ is bonded to four $\mathrm{O}$ anions in the form of a distorted tetrahedron, while $\mathrm{Ga}$ (II) forms a highly distorted octahedron with six $\mathrm{O}$ anions. Each $\mathrm{O}(\mathrm{I})$ is threefold coordinated and shared by two octahedra and one tetrahedron. Each $\mathrm{O}$ (II) is also threefold coordinated and lies at the intersection of two tetrahedra and one octahedron. Each $\mathrm{O}(\mathrm{III})$ is fourfold coordinated and connected with three octahedra and one tetrahedron. The computed bond lengths are as follows: $\mathrm{Ga}(\mathrm{I})-\mathrm{O}(\mathrm{I})=1.864 \AA, \mathrm{Ga}(\mathrm{I})-\mathrm{O}(\mathrm{II})=1.867 \AA$, Ga(I)-O(III) $=1.894 \AA$, $\mathrm{Ga}(\mathrm{II})-\mathrm{O}(\mathrm{I})=1.969 \AA, \mathrm{Ga}(\mathrm{II})-\mathrm{O}$ (II) $=1.951 \AA$, and $\mathrm{Ga}(\mathrm{II})-\mathrm{O}(\mathrm{III})=$ $2.073 \AA$. All are in good agreement with the experimental values. ${ }^{50}$

Five $\beta-\mathrm{Ga}_{2} \mathrm{O}_{3}$ surfaces of interest are created by cleaving the optimized bulk structure through the corresponding planes, and the resultant structures are depicted in Fig. 1(b-f). They are denoted as (100)-A, (100)-B, (001)-A, (001)-B and (010), respectively. Structural differences for these surfaces were intensively investigated by Bermudez. ${ }^{56}$ In order to estimate the relative stability of these surfaces, slabs with different numbers of stoichiometric repeated layers were constructed for each surface. The computed total energies of the slabs, together with their corresponding numbers of $\mathrm{Ga}_{2} \mathrm{O}_{3}$ units, were then fitted into the following equation to calculate the surface formation energy $\gamma$,

$$
\gamma=\left(E_{\text {slab }}-n E_{\mathrm{Ga}_{2} \mathrm{O}_{3}}\right) / 2 A
$$

where $E_{\text {slab }}$ is the total energy of the slab, $n$ is the number of $\mathrm{Ga}_{2} \mathrm{O}_{3}$ units in the slab, and $2 A$ is the total exposed area of the two identical sides of the slab.

As shown in Fig. 2, calculated surface energies are converged within $0.01-0.03 \mathrm{~J} \mathrm{~m}^{-2}$ for (100), (001) and (010) when $n$ reaches 4,8 , and 10 , respectively. The computed value of surface energy is $0.84 \mathrm{~J} \mathrm{~m}^{-2}$ for (100)-A, $0.47 \mathrm{~J} \mathrm{~m}^{-2}$ for (100)-B, $1.75 \mathrm{~J} \mathrm{~m}^{-2}$ for (001)-A, $1.18 \mathrm{~J} \mathrm{~m}^{-2}$ for (001)-B and $1.49 \mathrm{~J} \mathrm{~m}^{-2}$ for (010). Our results show that the (100)-B surface is the most stable one among the five surfaces we considered, which is in good agreement with available experimental and theoretical data. ${ }^{56-58}$ Therefore, we focus our calculations and discussions on the (100)-B surface in the following parts.

As shown in Fig. 1(c), the (100)-B surface is terminated by fivefold coordinated $\mathrm{Ga}$ (II) $\left(\mathrm{Ga}_{5 \mathrm{c}}\right.$ (II)) and threefold coordinated $\mathrm{O}$ (III) $\left(\mathrm{O}_{3 \mathrm{c}}(\mathrm{III})\right) . \mathrm{Ga}(\mathrm{I})$ and $\mathrm{O}(\mathrm{I})$ atoms at the surface are fully coordinated, and there are no $\mathrm{O}$ (II) atoms in the surface plane. The side view of this surface is like a wave. The quadrilaterals composed of $\mathrm{Ga}_{5 \mathrm{c}}$ (II),

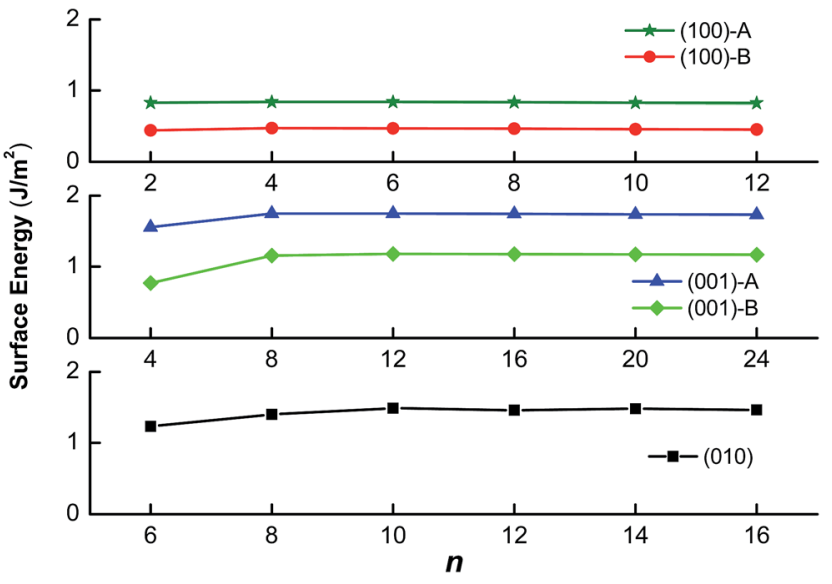

Fig. 2 Surface energies (in $\mathrm{J} \mathrm{m}^{-2}$ ) of fully optimized (100)-A, (100)-B, (001)-A, (001)-B and (010) surfaces of $\beta-\mathrm{Ga}_{2} \mathrm{O}_{3}$ as a function of the number $n$ of stoichiometric repeated layers.

$\mathrm{O}_{3 \mathrm{c}}$ (III) and $\mathrm{O}(\mathrm{I})$ atoms are located in the wave crest, while $\mathrm{Ga}(\mathrm{I})$ atoms are situated in the wave trough. Based on the relaxed surface structure of (100)-B, total density of states (TDOS) and partial density of states (PDOS) have been evaluated by means of HSE06. As shown in Fig. 3, the valence band maximum (VBM) is mainly composed of $\mathrm{O} 2 \mathrm{p}$ states, slightly hybridized with Ga $3 \mathrm{~d}$ and $4 \mathrm{p}$ states. Ga $4 \mathrm{~s}$ states contribute more to the lower valence bands. The conduction band minimum (CBM) consists mostly of Ga $4 \mathrm{~s}$ states. The valence bands exhibits the characteristic of mixed $\mathrm{O} 2 \mathrm{p}$, $\mathrm{Ga} 4 \mathrm{~s}, 4 \mathrm{p}$ and $3 \mathrm{~d}$ states. The strong mixing of $\mathrm{O}$ and $\mathrm{Ga}$ orbitals is indicative of the high degree of covalent bonding in this semiconductor. The value of the band gap is computed to be $4.0 \mathrm{eV}$, which is smaller than that of the bulk $(4.5 \mathrm{eV})$ due to the surface dangling bonds.

\subsection{Formation of $\mathrm{Ni}_{n}$ clusters on the (100)-B surface of $\beta$ - $\mathrm{Ga}_{2} \mathrm{O}_{3}$}

To obtain the most stable structure for a given $\mathrm{Ni}_{n}(n=1-4)$ cluster supported on $\mathrm{Ga}_{2} \mathrm{O}_{3}(100)$, the cluster was placed on the

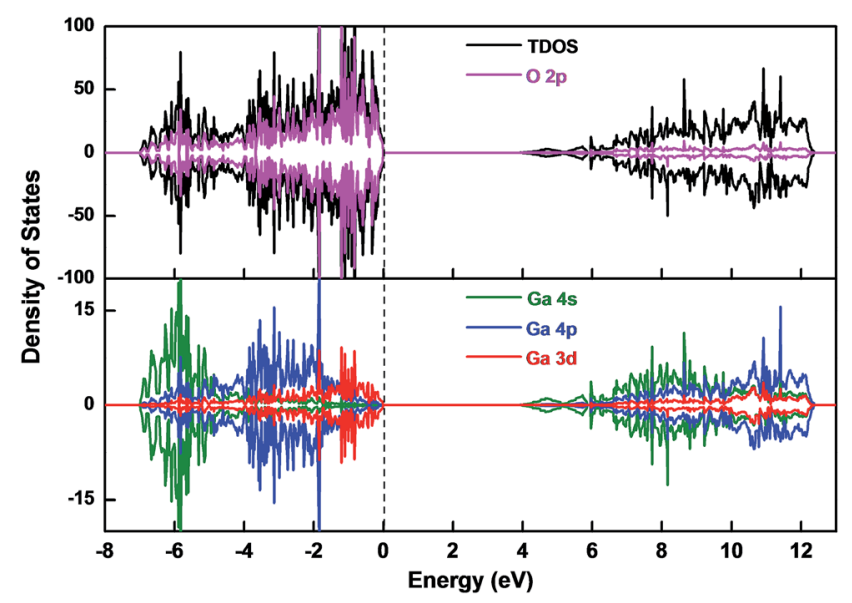

Fig. 3 Density of states for the (100)-B surface of $\beta-\mathrm{Ga}_{2} \mathrm{O}_{3}$ calculated by HSE06. The Fermi level is shown through the vertical dashed line. 
surface in all possible positions and in different orientations. The four most stable configurations for each $\mathrm{Ni}_{n} / \mathrm{Ga}_{2} \mathrm{O}_{3}(100)$ are shown in Fig. 4, while the other configurations are summarized in the ESI (see Fig. S1†). Relative energies with respect to the corresponding lowest-energy structures are shown in the figures. All of the obtained configurations show that after adding $\mathrm{Ni}_{n}$ clusters onto the surface, there are bonds formed between the cluster and surface, which are defined as
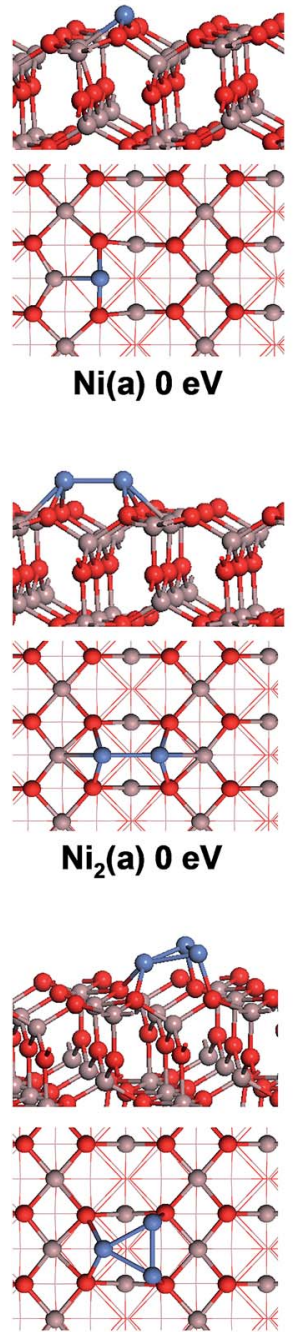

$\mathrm{Ni}_{3}($ a) $\mathrm{O} \mathrm{eV}$

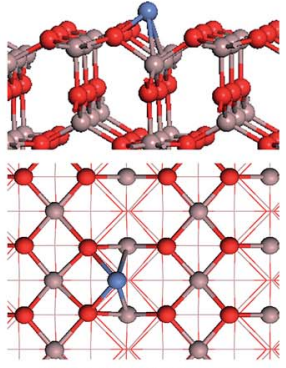

$\mathrm{Ni}(b) 0.09 \mathrm{eV}$
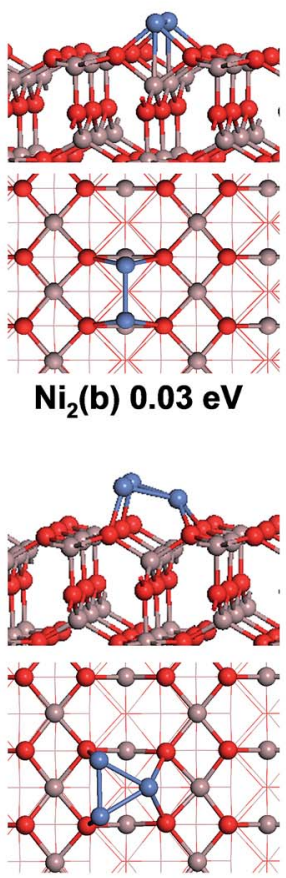

$\mathrm{Ni}_{3}$ (b) $0.02 \mathrm{eV}$

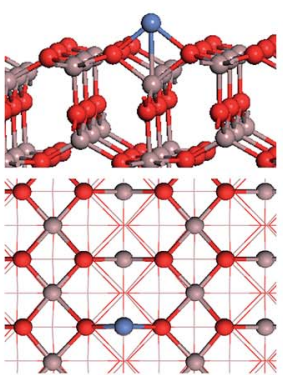

$\mathrm{Ni}(c) 0.18 \mathrm{eV}$
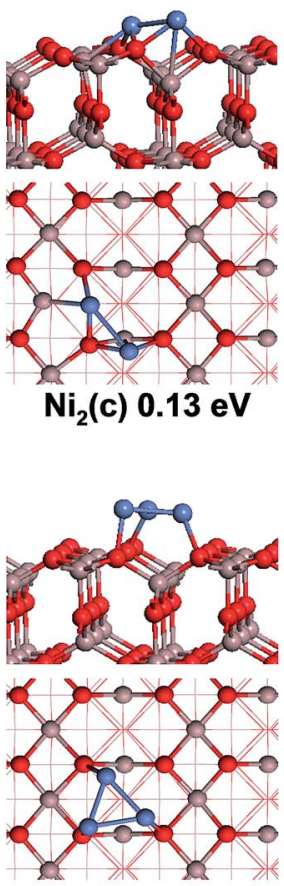

$\mathrm{Ni}_{3}(\mathrm{c}) 0.08 \mathrm{eV}$

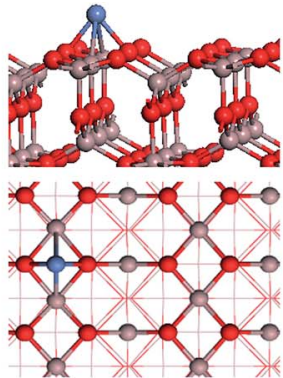

$\mathrm{Ni}(d) 0.44 \mathrm{eV}$
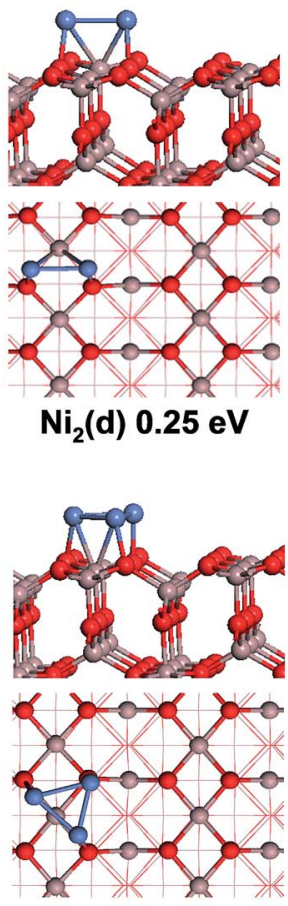

$\mathrm{Ni}_{3}(\mathrm{~d}) 0.12 \mathrm{eV}$
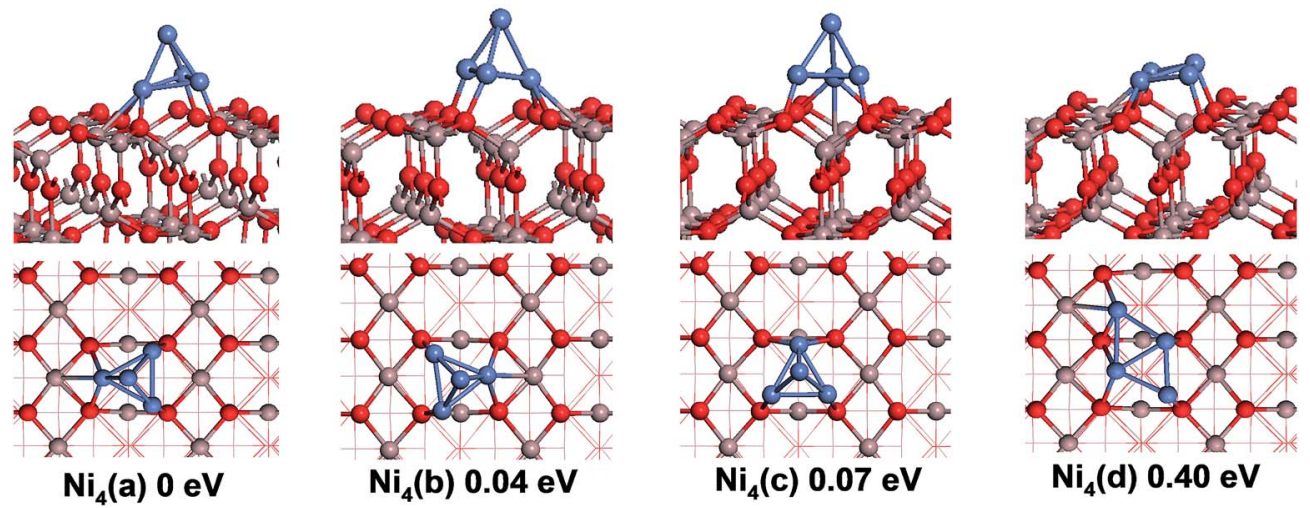

Fig. 4 Stable configurations of $\mathrm{Ni}_{n} / \mathrm{Ga}_{2} \mathrm{O}_{3}(100)(n=1-4)$ clusters (side and top views). Relative energies with respect to the corresponding lowest-energy structure are shown. Coloring scheme: red (surface O), brown (Ga) and blue (Ni). This color scheme applies to the following figure. 
"interfacial bonds" in this work. This means that the interaction between clusters and the $\mathrm{Ga}_{2} \mathrm{O}_{3}$ surface belongs to the chemical adsorption. The adsorption energy, $E_{\text {ads }}$, of a cluster adsorbed on the $\beta-\mathrm{Ga}_{2} \mathrm{O}_{3}$ surface was defined as:

$$
E_{\text {ads }}=E_{\text {total }}-E_{\text {surface }}-E_{\text {cluster }}
$$

where $E_{\text {total }}$ is the total energy of the $\mathrm{Ga}_{2} \mathrm{O}_{3}$ surface with a cluster, $E_{\text {surface }}$ is the total energy of the bare and relaxed surface, and $E_{\text {cluster }}$ is the energy of the optimized cluster in the gas phase. To better understand the nucleation or growth of $\mathrm{Ni}_{n}$ clusters on the support, the average binding energy $E_{\text {binding }}$ of $\mathrm{Ni}_{n}$ clusters adsorbed on the $\beta-\mathrm{Ga}_{2} \mathrm{O}_{3}$ surface was calculated as

$$
E_{\text {binding }}=\left(E_{\text {total }}-E_{\text {surface }}-n E_{\mathrm{Ni}}\right) / n
$$

where $E_{\mathrm{Ni}}$ is the energy carried by a free $\mathrm{Ni}$ atom in a vacuum.

The key structural parameters for the most stable configuration of each $\mathrm{Ni}_{n} / \mathrm{Ga}_{2} \mathrm{O}_{3}(100)$ ensemble are displayed in Fig. 5 . As shown in Fig. 5(a), the most stable adsorption site for an isolated $\mathrm{Ni}$ atom is in the middle of two nearest $\mathrm{O}_{3 \mathrm{c}}$ (III) atoms with an adsorption energy of $-2.16 \mathrm{eV}$, resulting in two $\mathrm{Ni}-\mathrm{O}$ bonds with an equal bond length of $1.856 \AA$, and the distance of $\mathrm{Ga}_{5 \mathrm{c}}$ (II) and the Ni atom to be $2.289 \AA$. The adsorption of the Ni atom increases the distance between the $\mathrm{O}_{3 \mathrm{c}}$ (III) atom and $\mathrm{Ga}_{5 \mathrm{c}}$ (II) atom by about $0.58 \AA$ compared with the value for a clean surface. The adsorption of the $\mathrm{Ni}$ monomer induces therefore significant surface modifications. We have tested the adsorption of a single $\mathrm{Ni}$ atom on top of a single $\mathrm{O}(\mathrm{III})$ or $\mathrm{O}(\mathrm{I})$ atom. In the optimized structure, the $\mathrm{Ni}$ atom migrated to the bridge position, which is the same as the most stable structure. This means that the Ni atom prefers a bridge adsorption between two oxygens instead of a top one on the surface oxygen atom. Comparing the relative energies of all $\mathrm{Ni}_{1} / \mathrm{Ga}_{2} \mathrm{O}_{3}$ optimized configurations from Fig. 4, one can notice that the formation of interfacial bonds between the $\mathrm{Ni}$ atom and the coordinatively saturated gallium/oxygen atoms from the surface

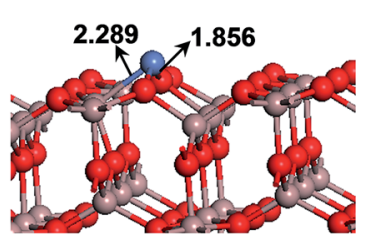

(a)

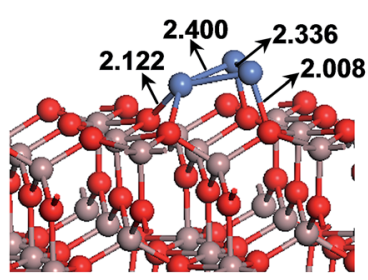

(c)

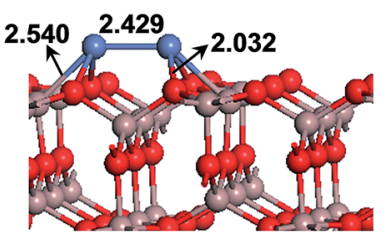

(b)

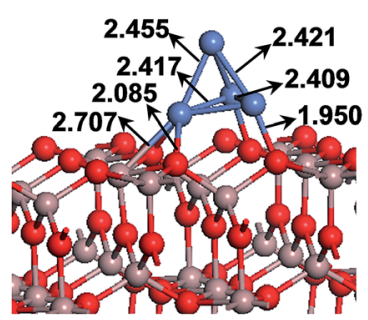

(d)
Fig. 5 Geometrical parameters for the most stable structures of $\mathrm{Ni}_{n} /$ $\mathrm{Ga}_{2} \mathrm{O}_{3}(100)(n=1-4)$ : (a) $\mathrm{Ni}$, (b) $\mathrm{Ni}_{2}$, (c) $\mathrm{Ni}_{3}$, and (d) $\mathrm{Ni}_{4}$. leads to less stable structures. Only the structure with the $\mathrm{Ni}$ binding to the $\mathrm{O}(\mathrm{III})$ and $\mathrm{Ga}$ (II) is stable, as it brings the three surface atoms to a coordination number similar to that in bulk $\mathrm{Ga}_{2} \mathrm{O}_{3}$.

When a $\mathrm{Ni}_{2}$ dimer is adsorbed on the $\mathrm{Ga}_{2} \mathrm{O}_{3}(100)$ surface, the most energetically favorable configuration is the horizontal adsorption (see Fig. 4), with an adsorption energy of $-2.47 \mathrm{eV}$. The two Ni atoms are symmetrically located on the surface, forming six interfacial bonds. Owing to the adsorption of the additional $\mathrm{Ni}$ atom, the already bonded $\mathrm{Ni}$ atom is lifted and the bond length of $\mathrm{Ni}-\mathrm{O}$ is computed to be $2.032 \AA(+0.18 \AA$ compared with the Ni-O bond from Ni/ $\left.\mathrm{Ga}_{2} \mathrm{O}_{3}(100)\right)$. Similarly, the $\mathrm{Ga}-\mathrm{Ni}$ bond is also lengthened by $0.25 \AA$. The calculated distance between the two Ni atoms is $2.429 \AA$, which is longer than that within the $\mathrm{Ni}_{2}$ cluster in the gas phase by $0.065 \AA$. As shown in Fig. $\mathrm{S} 1, \dagger$ like in the case of the Ni monomer, more bond formation between the $\mathrm{Ni}_{2}$ cluster and the fully saturated $\mathrm{Ga}$ and $\mathrm{O}$ atoms from the surface lead to less favorable structures. The average binding energy of the most stable structure is calculated to be $-2.20 \mathrm{eV}$, which suggests that the addition of the second Ni atom slightly improves the stability of the first $\mathrm{Ni}$ atom.

There are two stable configurations for the isolated $\mathrm{Ni}_{3}$ ternary cluster: the regular triangular form and the beeline form, and the latter is calculated to be more stable than the former by $0.12 \mathrm{eV}$. These two initial structures of the $\mathrm{Ni}_{3}$ cluster were attached to the surface in different directions and positions. After optimization, some original linear configurations are curled (see structures $\mathrm{i}$ and $\mathrm{k}$ in Fig. $\mathrm{S} 1 \dagger$ ). Our calculations show that the total energy of the triangular configurations is always lower than that of the linear ones. For the lowest-energy structure (see Fig. 4 and 5(c)), one Ni atom is located in the most stable adsorption site for single Ni atom attached to the surface, and the other two Ni atoms symmetrically form bonds with $\mathrm{O}(\mathrm{I})$ atoms. The $\mathrm{Ni}-\mathrm{O}(\mathrm{III}) / \mathrm{O}(\mathrm{I})$ and $\mathrm{Ni}-\mathrm{Ni}$ bonds are predicted to be $2.122 \AA / 2.008 \AA$ and $2.336-2.400 \AA$, respectively. The Ni-Ni bonds within the triangular form are shorter and stronger than those in the adsorbed dimer. Corroborating this with the larger average binding energy for $\mathrm{Ni}_{3}$ cluster on the surface $(-2.28 \mathrm{eV})$, it suggests that the formation of the $\mathrm{Ni}_{3}$ cluster is favorable on the surface.

The initial adsorption configurations for the $\mathrm{Ni}_{4}$ cluster were set to be tetrahedral and rhombic. The tetrahedral structure is computed to be energetically more favorable than the rhombic one by $0.10 \mathrm{eV}$ in the gas phase. Ten stable adsorption configurations were obtained after optimizations, as displayed in Fig. 4 and $\mathrm{S} 1 . \dagger$ The results show that the adsorption of the tetrahedral $\mathrm{Ni}_{4}$ cluster is energetically more favorable than that of the rhombic one. As shown in Fig. 5(d), the most stable configuration is generated by adding an extra $\mathrm{Ni}$ atom above the plane of the $\mathrm{Ni}_{3}$ cluster in the lowest-energy structure of $\mathrm{Ni}_{3}$ / $\mathrm{Ga}_{2} \mathrm{O}_{3}(100)$. The introduction of the extra $\mathrm{Ni}$ atom decreases the average binding energy to $-2.34 \mathrm{eV}$, and further improves the stability of the $\mathrm{Ni}_{n}$ cluster on the $\beta-\mathrm{Ga}_{2} \mathrm{O}_{3}$ surface. The $\mathrm{Ni}-\mathrm{O}(\mathrm{I}) /$ $\mathrm{O}$ (III) and Ni-Ga bonds are calculated to be $1.95 \AA / 2.085 \AA$ and $2.707 \AA$, respectively. The $\mathrm{Ni}-\mathrm{Ni}$ bonds are in the range of $2.409-$ $2.455 \AA$. 
Our calculated results show that the addition of a new $\mathrm{Ni}$ atom to an existing $\mathrm{Ni}_{n}$ cluster adsorbed on the $\mathrm{Ga}_{2} \mathrm{O}_{3}(100)$ surface is energetically favorable. If the $\mathrm{Ni}_{n}$ cluster binds to coordinatively saturated $\mathrm{Ga}(\mathrm{I})$ atoms from the surface, the adsorption structure is energetically unfavorable. The average binding energy gradually decreases with the increase of $n$ value in the $\mathrm{Ni}_{n}$ cluster, which indicates a tendency for this metal to aggregate on the surface. The most stable configuration of every $\mathrm{Ni}_{n}$ cluster $(n=1-4)$ indicates that one $\mathrm{Ni}$ cluster tends to form above $\mathrm{Ga}(\mathrm{I})$ atoms and between $\mathrm{O}(\mathrm{I})$ and $\mathrm{O}_{3 \mathrm{c}}$ (III) atoms.

To investigate the charge rearrangement upon the formed interface between the $\mathrm{Ga}_{2} \mathrm{O}_{3}$ surface and $\mathrm{Ni}_{n}$ cluster, Bader charge analysis has been performed. ${ }^{59,60}$ The optimized geometries of the surface with the adsorbed cluster, clean surface, and isolated cluster are kept fixed for the Bader charge analyses. The results shown in Table 1 demonstrate that when a $\mathrm{Ni}_{n}$ cluster is adsorbed onto the $\beta-\mathrm{Ga}_{2} \mathrm{O}_{3}(100)$ surface, it will lose electrons and carry some positive charge. It is interesting to note that for the three-dimensional $\mathrm{Ni}_{4}$ cluster adsorbed system, only the $\mathrm{Ni}$ atoms bonded to the surface donate electrons to the surface, while the Ni atom at the top of the tetrahedron is nearly neutral, which indicates that at low metal coverage, the nickel adatom is ionic because it is directly bonded to surface oxygen; with the increase of the coverage, the newly arrived nickel adatoms are neutral unless they are bonded to the surface atoms.

In order to understand the effect of adsorbing the metal cluster on the electronic structure of the substrate, we have calculated the TDOS and PDOS for Ni 3d states for the lowestenergy configurations of $\mathrm{Ni}_{n} / \mathrm{Ga}_{2} \mathrm{O}_{3}(100)$. As shown in Fig. 6, for the $\mathrm{Ni}_{n} / \mathrm{Ga}_{2} \mathrm{O}_{3}(n=1,3$ and 4$)$ system, there is an unoccupied $\mathrm{Ni}$ state about $2 \mathrm{eV}$ above the Fermi level. As shown in Fig. 3, the CBM of the $\mathrm{Ga}_{2} \mathrm{O}_{3}$ surface is mainly composed of $\mathrm{Ga} 4 \mathrm{~s}$ orbitals. So the empty Ni state overlaps with the empty Ga states. Upon photoexcitation, electrons removed from the $\mathrm{O}$ occupied states move to the Ga unoccupied states. As the Ga unoccupied states overlap with the unoccupied Ni state, the electron can transfer from $\mathrm{Ga}$ to Ni. Consequently, the accumulating electrons on the $\mathrm{Ni}_{n}$ cluster may participate in proton reduction for HER. From Fig. 6, one can also find that remarkable occupied states of $\mathrm{Ni}$ appear in VBM of the system. During the photocatalytic reaction, an electron can be excited from an $\mathrm{O}$ atom to an unoccupied $\mathrm{Ga}$ atom. This results in the formation of a hole on the $\mathrm{O}$ atom. The hole can be moved from the $\mathrm{O}$ atom to the $\mathrm{Ni}$ atom in the $\mathrm{Ni}_{n}$ cluster. So in principle $\mathrm{Ni}$ atoms can also contribute to the OER. However, using the Ni metal for the OER is not really appropriate because it will probably lead to NiO.

\subsection{Formation of $(\mathrm{NiO})_{n}$ clusters on the (100)-B surface of $\beta$ - $\mathrm{Ga}_{2} \mathrm{O}_{3}$}

For $(\mathrm{NiO})_{n} / \mathrm{Ga}_{2} \mathrm{O}_{3}(100)$, the most stable energy structures obtained from our calculations are plotted in Fig. 7, and other less stable structures are shown in Fig. S2. $\dagger$ For every composition, key structural parameters of the lowest-energy configurations are summarized in Fig. 8. The adsorption energy for clusters is calculated based on eqn (2), and the obtained results are shown in Table 1 . Negative adsorption energy means that the adsorbed structure is stable.

For the $\mathrm{NiO} / \mathrm{Ga}_{2} \mathrm{O}_{3}(100)$ system, the most stable structure for this composition is obtained by introducing an additive oxygen atom to the most stable structure of $\mathrm{Ni} / \mathrm{Ga}_{2} \mathrm{O}_{3}$. As shown in Fig. 8(a), the $\mathrm{O}$ atom binds to the surface $\mathrm{Ga}_{5 \mathrm{c}}$ (II) atom through a bond length of $1.885 \AA$ A. Due to the adsorption of the $\mathrm{O}$ atom, the bonded $\mathrm{Ni}$ atom is lifted and the bond length of $\mathrm{Ni}-\mathrm{O}_{3 \mathrm{c}}(\mathrm{III})$ is lengthened by $0.18 \AA$ compared with that of the single $\mathrm{Ni}$ atom adsorbed on the surface. The Ni-O bond is computed to be $1.776 \AA$. The adsorption energy of the NiO cluster is calculated to be $-1.92 \mathrm{eV}$, indicating the stability of this configuration.

In the case of $(\mathrm{NiO})_{2} / \mathrm{Ga}_{2} \mathrm{O}_{3}(100)$, seven structures are obtained as shown in Fig. 7 and $\mathrm{S} 2 . \dagger$ The lowest-energy configuration consists of a $-\mathrm{Ni}-\mathrm{O}-\mathrm{Ni}-\mathrm{O}-$ four-membered ring adsorbed above the rhombic fragment of $-\mathrm{O}-\mathrm{Ga}-\mathrm{O}-\mathrm{Ga}-$ with the formation of four interfacial bonds. As can be seen from Fig. 8(b), the bond lengths of Ga-O, Ni-O(III) and Ni-O(I) are computed to be $2.000 \AA$, $1.940 \AA$ and $1.935 \AA$, respectively. The average distance of the $\mathrm{Ni}-\mathrm{O}$ bonds within the cluster is $1.886 \AA$, which is larger by $0.11 \AA$ than that in the NiO monomer supported on the $\mathrm{Ga}_{2} \mathrm{O}_{3}(100)$ surface. The adsorption energy of this structure is predicted to be $-3.67 \mathrm{eV}$, which is lower than that of $\mathrm{NiO}$ adsorption by $1.65 \mathrm{eV}$. Examining the relative energy of different structures from Fig. 7 and $\mathrm{S} 2, \dagger$ one can find that the structure with $\mathrm{Ni}_{2} \mathrm{O}_{2}$ located above $\mathrm{Ga}(\mathrm{I})$ atoms as well as between $\mathrm{O}(\mathrm{I})$ and $\mathrm{O}_{3 \mathrm{c}}(\mathrm{III})$ atoms is less stable than the one with $\mathrm{Ni}_{2} \mathrm{O}_{2}$ situated above the rhombic fragment of $-\mathrm{O}-\mathrm{Ga}-\mathrm{O}-\mathrm{Ga}-$.

When a $(\mathrm{NiO})_{3}$ cluster was attached to the surface, both three-dimensional and two-dimensional models were considered. The most stable structure is a two-dimensional planar sixmember ring structure located atop of the rhombic fragment of -O-Ga-O-Ga-, and with an adsorption energy of $-2.57 \mathrm{eV}$. As shown in Fig. 8(c), the three Ni atoms are coordinated to surface oxygen atoms with $\mathrm{Ni}-\mathrm{O}$ bonds of $2.012,2.045$ and $2.039 \AA$,

Table 1 The adsorption energy $E_{\text {ads }}(\mathrm{eV})$, binding energy $E_{\text {nuc }}(\mathrm{eV})$ and the change of the total Bader charge for $\mathrm{Ni}_{n}$ or $\mathrm{Ni}_{n} \mathrm{O}_{n}$ clusters $\left(\mathrm{a} . \mathrm{u}\right.$.) in $\mathrm{Ni}_{n} /$ $\mathrm{Ga}_{2} \mathrm{O}_{3}$ or $\mathrm{Ni}_{n} \mathrm{O}_{n} / \mathrm{Ga}_{2} \mathrm{O}_{3}$ systems, respectively. Only the most stable configuration for each composition is listed

\begin{tabular}{|c|c|c|c|c|c|c|c|c|}
\hline Configuration & $E_{\text {ads }}$ & $E_{\text {binding }}$ & $Q_{\text {cluster }}$ & Configuration & $E_{\text {ads }}$ & $Q_{\mathrm{Ni}}$ & $Q_{\mathrm{O}}$ & $Q_{\text {cluster }}$ \\
\hline $\mathrm{Ni}$ & -2.16 & -2.16 & +0.58 & $\mathrm{NiO}$ & -1.92 & +0.35 & -0.30 & +0.05 \\
\hline $\mathrm{Ni}_{2}$ & -2.47 & -2.20 & +0.73 & $\mathrm{Ni}_{2} \mathrm{O}_{2}$ & -3.67 & +0.45 & -0.35 & +0.10 \\
\hline $\mathrm{Ni}_{4}$ & -6.83 & -2.34 & +0.78 & $\mathrm{Ni}_{4} \mathrm{O}_{4}$ & -2.96 & +2.18 & -2.12 & +0.06 \\
\hline
\end{tabular}



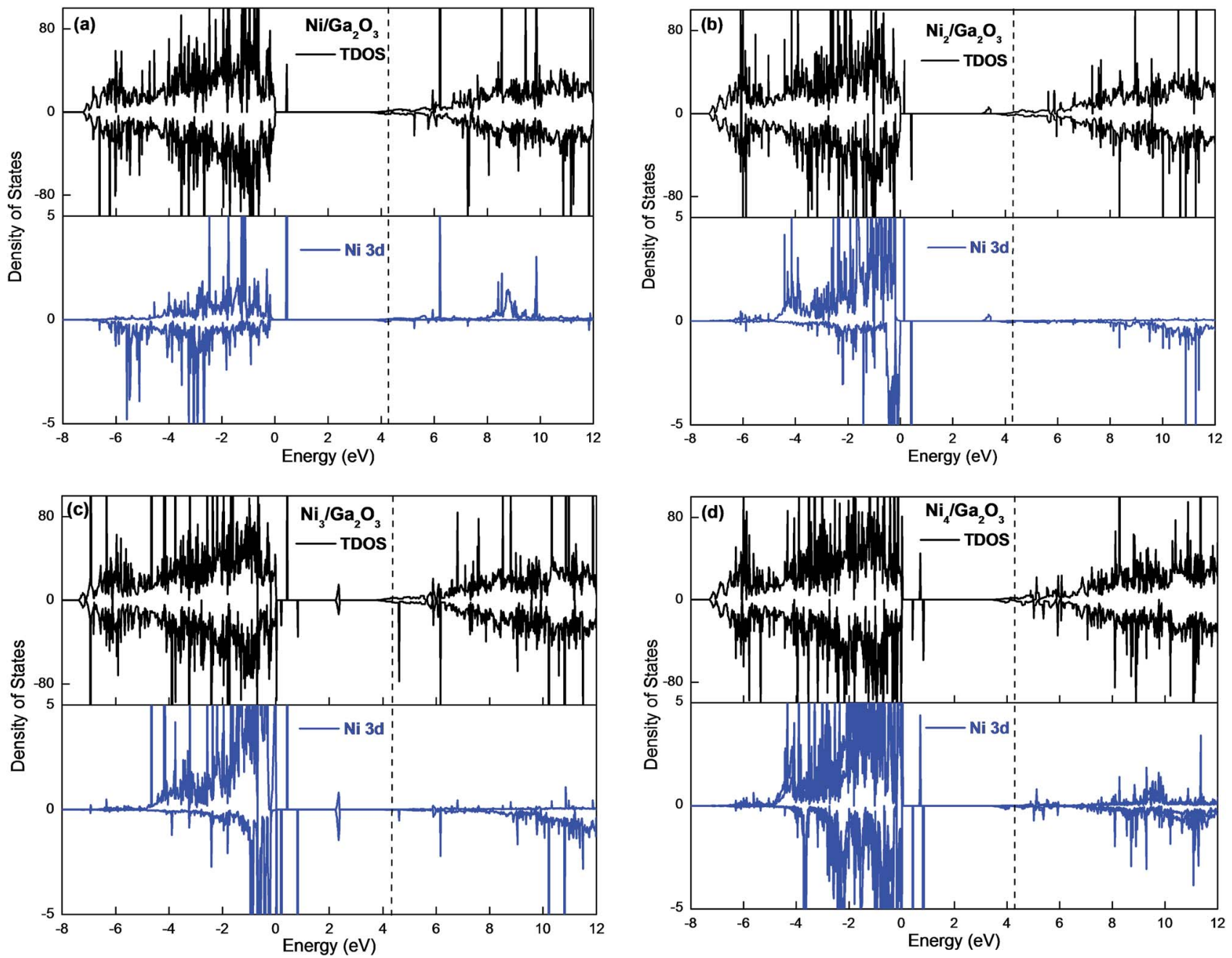

Fig. 6 Density of states for the most stable configuration of (a) $\mathrm{Ni}$, (b) $\mathrm{Ni}_{2}$, (c) $\mathrm{Ni}_{3}$, and (d) $\mathrm{Ni}_{4}$ adsorbed on the $\mathrm{Ga}_{2} \mathrm{O}_{3}(100)$ surface. The Fermi level is shown by the vertical dashed line.

respectively. Two oxygen atoms from the cluster bind to $\mathrm{Ga}$ atoms from the surface and have $\mathrm{Ga}-\mathrm{O}$ distances of 1.961 and $1.982 \AA$, respectively. The third oxygen from cluster does not connect to any $\mathrm{Ga}$ atom. The calculated $\mathrm{Ni}-\mathrm{O}$ bond lengths in cluster are in the range of 1.797-1.910 А.

For the $\mathrm{Ni}_{4} \mathrm{O}_{4}$ cluster adsorbed on the $\mathrm{Ga}_{2} \mathrm{O}_{3}(100)$ surface, several initial configurations have been optimized. For the most stable structure a, shown in Fig. 7 and in Fig. 8(d), the adsorbed cluster is symmetrically bonded to the surface by four Ni-O and two Ga-O bonds. Two Ni atoms bond to two $\mathrm{O}(\mathrm{I})$ with equal distances of $1.938 \AA$, while the other two Ni atoms bond to two O(III) with equal distances of $1.937 \AA$. Two oxygen atoms from the cluster form bonds with 5 -fold coordinated $\mathrm{Ga}$ atoms from the surface, with Ga-O distances of $2.038 \AA$ and $2.042 \AA$. The other two oxygen atoms from the cluster bind only internally in the cluster, and have no connection to the surface. The eightmember ring of the $\mathrm{Ni}_{4} \mathrm{O}_{4}$ cluster is made up from two kinds of $\mathrm{Ni}-\mathrm{O}$ bonds with distances of 1.764 and $1.870 \AA$, respectively. The second most stable structure b, displayed in Fig. 7, shows a rectangle cluster composed of three -Ni-O- four-member rings parallelly adsorbed on the surface, which is less stable by 0.18 $\mathrm{eV}$ than the lowest-energy structure. The third most stable structure c exhibits a cubic $\mathrm{Ni}_{4} \mathrm{O}_{4}$ cluster connected to the surface $\mathrm{Ga}$ and $\mathrm{O}$ atoms and located in the same site of the surface as the $\mathrm{Ni}_{2} \mathrm{O}_{2}$ cluster. Compared with the most stable structure, this configuration is energetically less favorable by $0.45 \mathrm{eV}$. In the gas phase, the rectangle $\mathrm{Ni}_{4} \mathrm{O}_{4}$ cluster in structure $\mathbf{b}$ is calculated to be the most stable, which is lower than the cluster in structure a and the cubic cluster in structure $\mathbf{c}$ by $0.04 \mathrm{eV}$ and $0.87 \mathrm{eV}$, respectively. The adsorption energies computed for the $\mathrm{Ni}_{4} \mathrm{O}_{4}$ clusters on the surface are of $-2.96 \mathrm{eV}$ for the most stable configuration $\mathbf{a},-2.74 \mathrm{eV}$ for structure $\mathbf{b}$, and $-3.35 \mathrm{eV}$ for structure c. These results suggest that the cubic $\mathrm{Ni}_{4} \mathrm{O}_{4}$ cluster adsorbs stronger on the $\mathrm{Ga}_{2} \mathrm{O}_{3}$ surface than on the planar structures.

As indicated from the calculations above, $(\mathrm{NiO})_{n}$ clusters tend to maximize interfacial bonds with coordinatively unsaturated $\mathrm{Ga}$ and $\mathrm{O}$ atoms of the $\mathrm{Ga}_{2} \mathrm{O}_{3}(100)$ surface. The calculated adsorption energies of low-energy structures indicate that there are strong interactions between nickel 

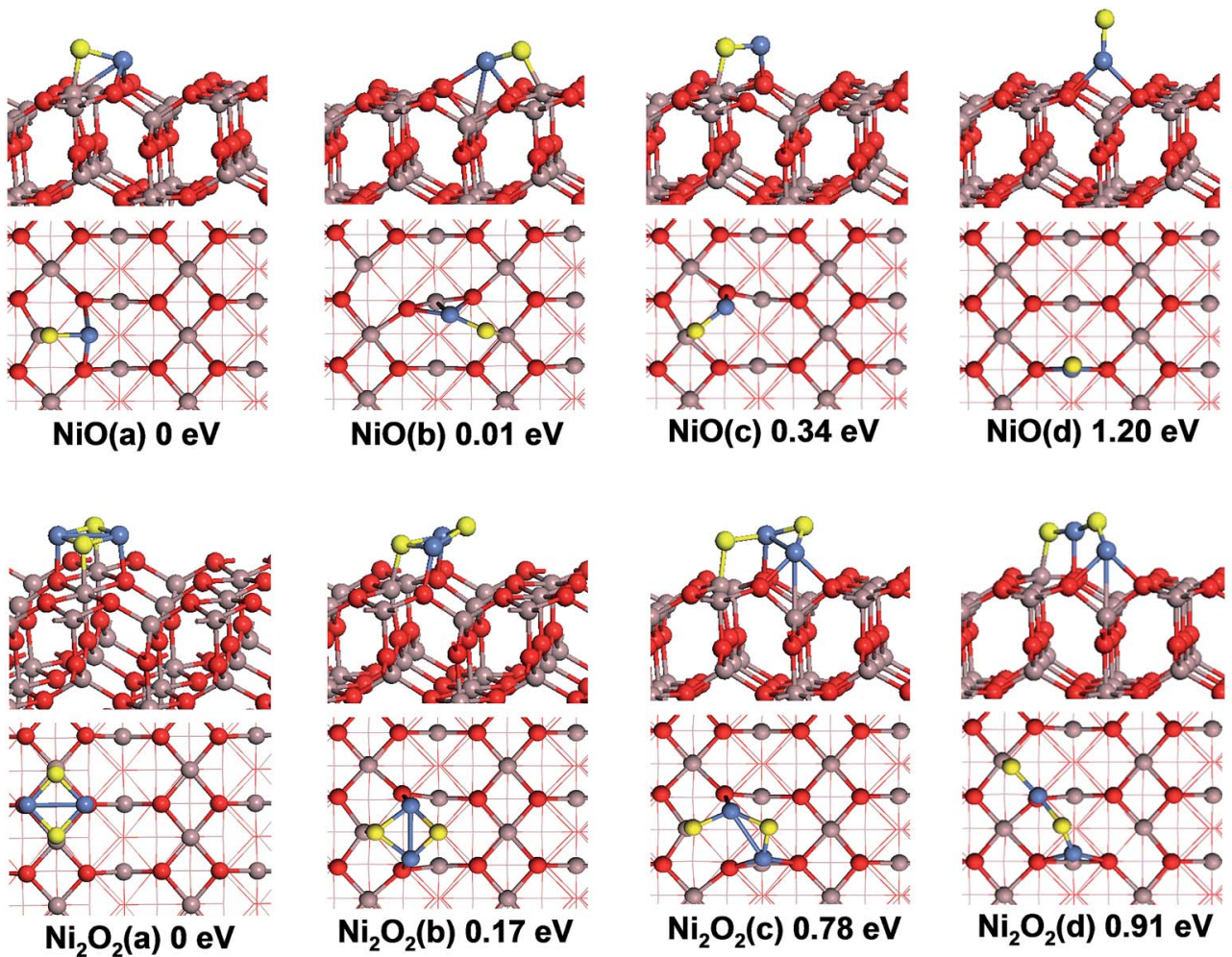

$\mathrm{Ni}_{2} \mathrm{O}_{2}(\mathrm{c}) 0.78 \mathrm{eV}$

$\mathrm{Ni}_{2} \mathrm{O}_{2}$ (d) $0.91 \mathrm{eV}$
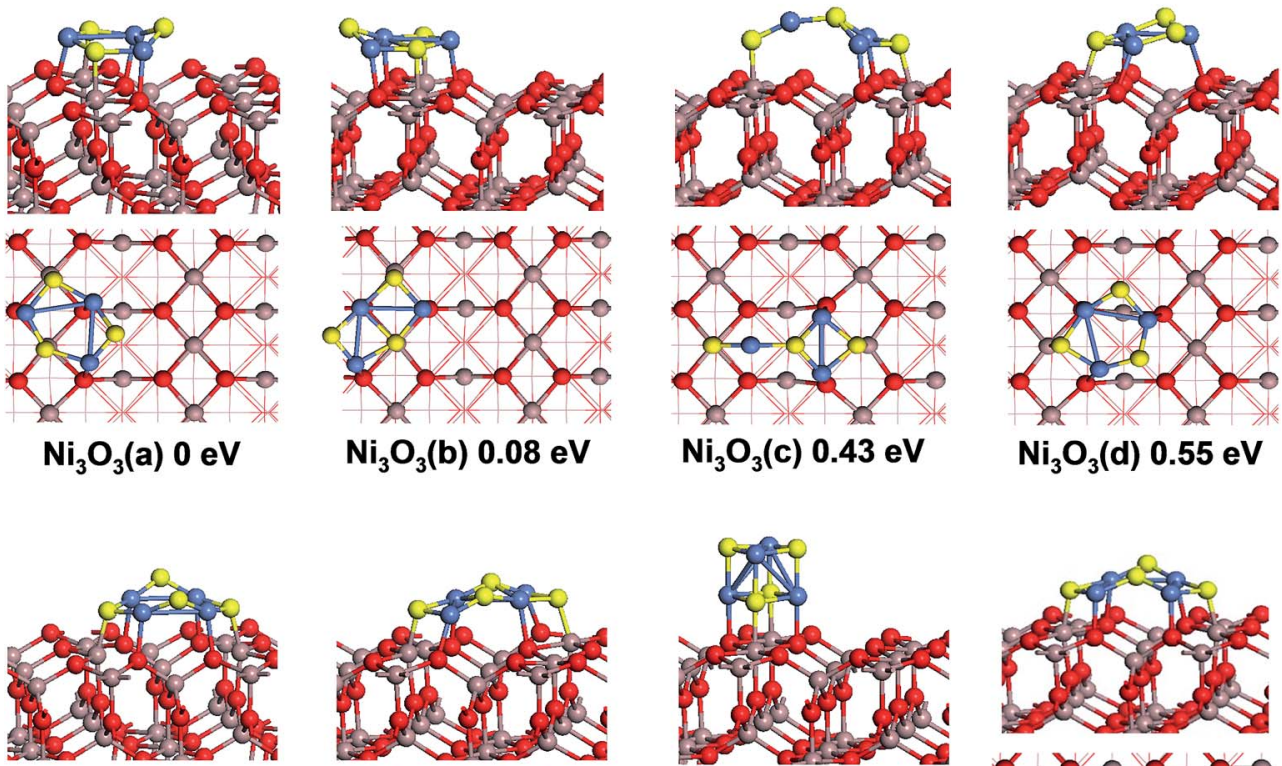

$\mathrm{Ni}_{3} \mathrm{O}_{3}(\mathrm{c}) 0.43 \mathrm{eV}$

$\mathrm{Ni}_{3} \mathrm{O}_{3}(\mathrm{~d}) 0.55 \mathrm{eV}$
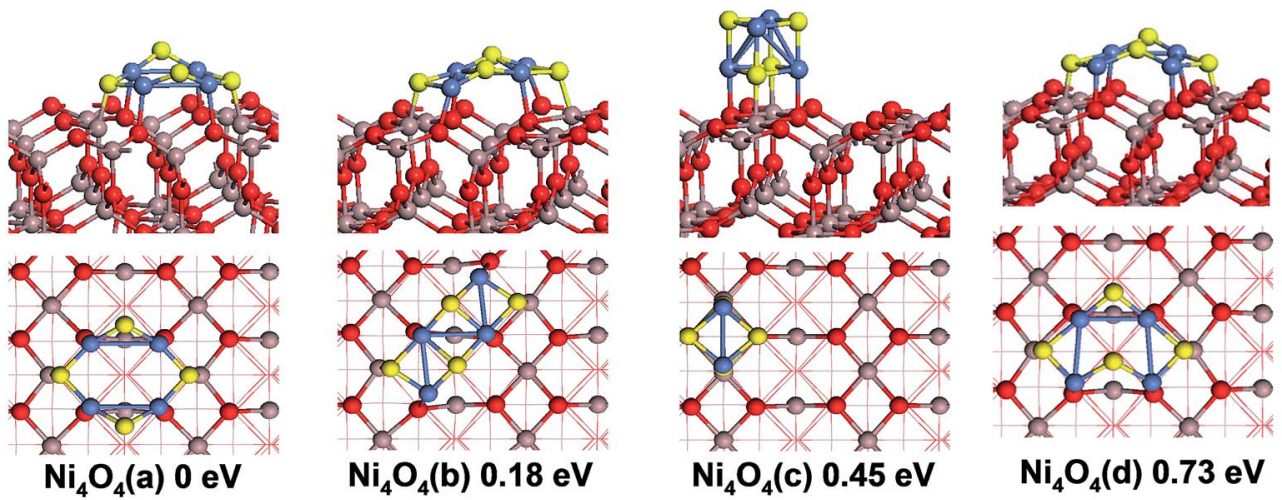

$\mathrm{Ni}_{4} \mathrm{O}_{4}(\mathrm{~d}) 0.73 \mathrm{eV}$

Fig. 7 Stable configurations of $\mathrm{Ni}_{n} \mathrm{O}_{n} / \mathrm{Ga}_{2} \mathrm{O}_{3}(100)(n=1-4)$ clusters (side and top views). Relative energies with respect to the corresponding lowest-energy structure are shown. Coloring scheme: red (surface O), brown (Ga), yellow (adsorbed O) and blue (Ni). The same color scheme applies to all the following figures. 


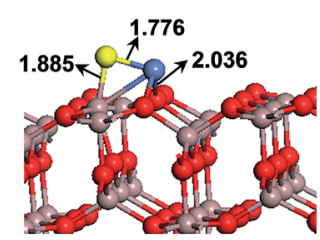

(a)

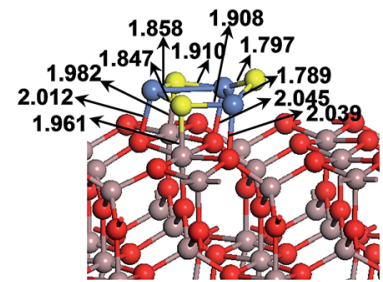

(c)

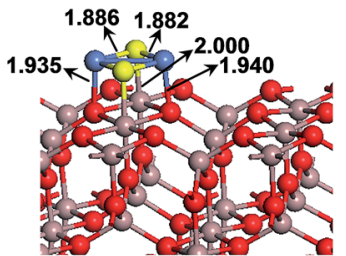

(b)

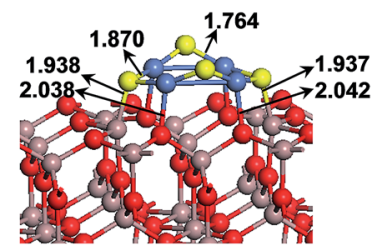

(d)
Fig. 8 Geometrical parameters for the most stable structures of $\mathrm{Ni}_{n} \mathrm{O}_{n} / \mathrm{Ga}_{2} \mathrm{O}_{3}(100)(n=1-4):$ (a) $\mathrm{Ni},\left(\right.$ b) $\mathrm{Ni}_{2}$, (c) $\mathrm{Ni}_{3}$, and (d) $\mathrm{Ni}_{4}$.

oxide nanoclusters and the surface. Unlike $\mathrm{Ni}_{n}$ clusters, $(\mathrm{NiO})_{n}$ clusters prefer to be formed above the rhombic fragment composed of $\mathrm{Ga}_{5 \mathrm{c}}(\mathrm{III}), \mathrm{O}(\mathrm{I})$ and $\mathrm{O}_{3 \mathrm{c}}(\mathrm{III})$ atoms. In other words, small $\mathrm{Ni}_{n}$ and $(\mathrm{NiO})_{n}$ clusters will tend to form on different sites of the surface.

The charge distribution at the interface between the $(\mathrm{NiO})_{n}$ clusters and the surface has been examined through the use of the Bader charge analysis. As shown in Table 1, after attaching to the surface, the $\mathrm{Ni}$ atoms from the $(\mathrm{NiO})_{n}$ clusters show positive charge while the $\mathrm{O}$ negative charge. This indicates that the charge flow occurs from $\mathrm{Ni}$ atoms to surface $\mathrm{O}$ atoms, and from surface $\mathrm{Ga}$ atoms to cluster $\mathrm{O}$ atoms simultaneously. The number of electrons received by $\mathrm{O}$ in $(\mathrm{NiO})_{n}$ clusters is slightly smaller than the number of electrons given away by $\mathrm{Ni}$. As a result, the total charge on the $(\mathrm{NiO})_{n}$ cluster is slightly positive. With the increase of the cluster size, the amount of the charge transferred between the surface and the cluster increases significantly due to the larger number of bonds formed between the surface and the cluster.

More insight into the adsorption effects of the $(\mathrm{NiO})_{n}$ clusters can be obtained from the analysis of the electronic density of states. In Fig. 9 we present the calculated HSE06 TDOS and PDOS for Ni 3d states and $\mathrm{O} 2 \mathrm{p}$ states for every $(\mathrm{NiO})_{n}$ cluster in the most stable adsorbed configuration. The strong mixing of $\mathrm{O}$ and Ni states is indicative of the covalent bonding in NiO. Some of mixed states are located in VBM and others are at and below
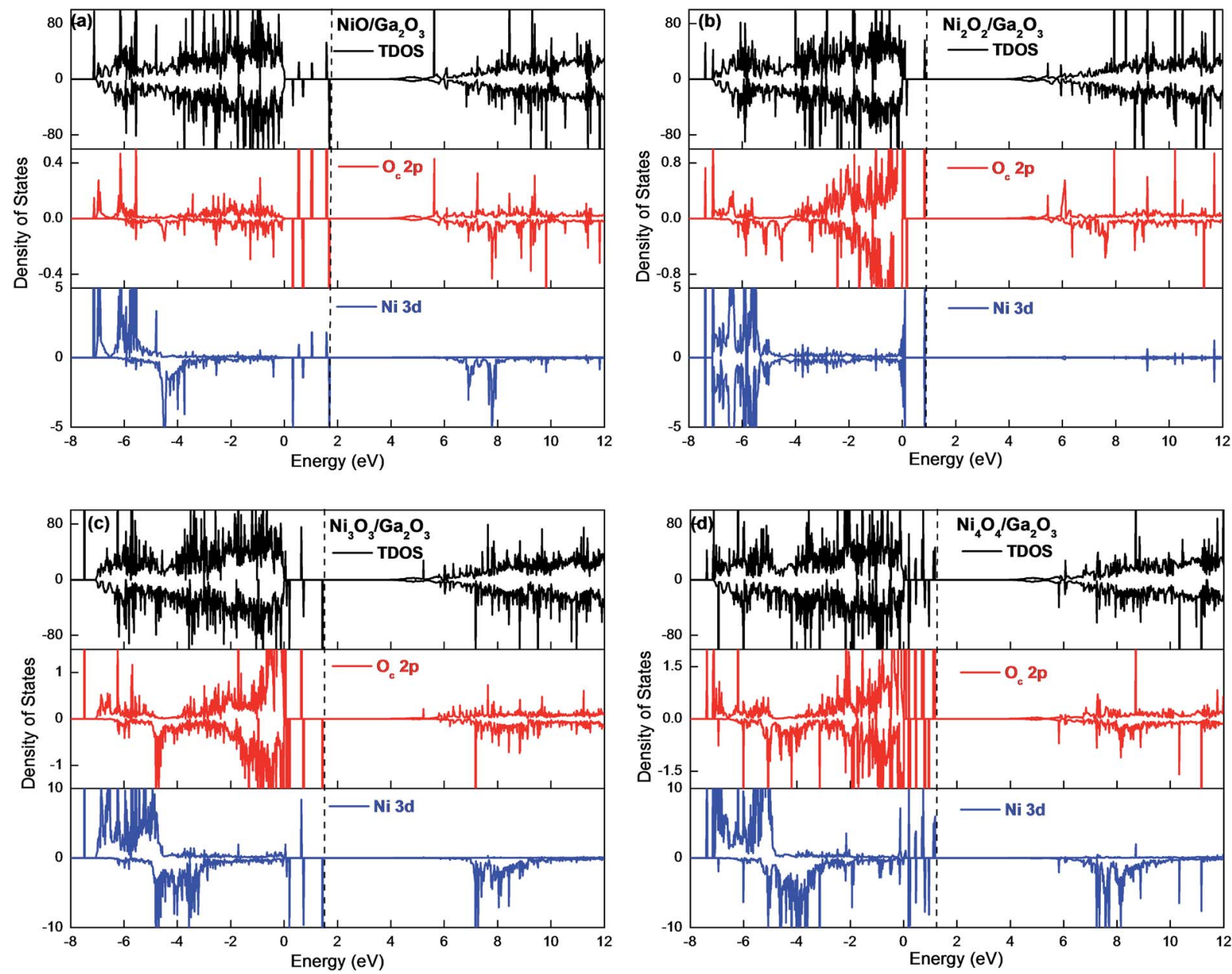

Fig. 9 Density of states for the most stable configuration of (a) $\mathrm{NiO}$, (b) $\mathrm{Ni}_{2} \mathrm{O}_{2}$, (c) $\mathrm{Ni}_{3} \mathrm{O}_{3}$ and (d) $\mathrm{Ni}_{4} \mathrm{O}_{4}$ adsorbed on the $\mathrm{Ga}_{2} \mathrm{O}_{3}(100)$ surface. The Fermi level is shown by the vertical dashed line. 
the Fermi level. Upon light irradiation, the electrons in the VBM of $\mathrm{Ga}_{2} \mathrm{O}_{3}$ are excited to the CBM, while the holes are left in the VBM. Since the occupied states from the $(\mathrm{NiO})_{n}$ cluster are higher in energy than the VBM, the electrons in $(\mathrm{NiO})_{n}$ tend to transfer to the VBM of $\mathrm{Ga}_{2} \mathrm{O}_{3}$. And then the holes generated in $(\mathrm{NiO})_{n}$ clusters will participate in the photocatalytic OER. As shown in Fig. 9, one can find that some Ni unoccupied states are located $\sim 4.5 \mathrm{eV}$ above the Fermi level. The high position of the Ni unoccupied states will make the HER unfavorable.

\section{Conclusions}

In this work, we have performed a systematic DFT study on the relative stabilities of the low-index surfaces of $\beta-\mathrm{Ga}_{2} \mathrm{O}_{3}$, and on the stable adsorption sites for $\mathrm{Ni}_{n}$ and $(\mathrm{NiO})_{n}$ clusters supported on the surface. It was found that small $\mathrm{Ni}_{n}$ clusters tend to be formed above $\mathrm{Ga}(\mathrm{I})$ atoms and between $\mathrm{O}(\mathrm{I})$ and $\mathrm{O}_{3 \mathrm{c}}(\mathrm{III})$ atoms, while $(\mathrm{NiO})_{n}$ clusters tend to grow on the rhombic fragment composed of $\mathrm{Ga}_{5 \mathrm{c}}(\mathrm{III}), \mathrm{O}(\mathrm{I})$ and $\mathrm{O}_{3 \mathrm{c}}$ (III) atoms. For $\mathrm{Ni}_{n} / \mathrm{Ga}_{2} \mathrm{O}_{3}$ systems, the binding energy decreases with the increment of $\mathrm{Ni}$ coverage (from $\mathrm{Ni}_{1}$ to $\mathrm{Ni}_{4}$ ), which indicates that larger clusters are energetically more stable than smaller ones. $(\mathrm{NiO})_{n}$ clusters are found to strongly adsorb on the $\mathrm{Ga}_{2} \mathrm{O}_{3}$ surface due to the negative adsorption energies within $-1.9 \mathrm{eV}$ to $-3.7 \mathrm{eV}$.

The electronic structure analyses indicate that for $\mathrm{Ni}_{n} / \mathrm{Ga}_{2} \mathrm{O}_{3}$ systems, the unoccupied Ni states overlap with the $\mathrm{Ga}$ unoccupied states. Upon the irradiation of light, the excited electron can transfer from $\mathrm{Ga}$ to Ni. Consequently, the accumulating electrons on $\mathrm{Ni}_{n}$ clusters may participate in the photocatalytic HER. As to $(\mathrm{NiO})_{n} / \mathrm{Ga}_{2} \mathrm{O}_{3}$, occupied states from the $(\mathrm{NiO})_{n}$ cluster may accept the holes from $\mathrm{O}$ atoms in the $\mathrm{Ga}_{2} \mathrm{O}_{3}$ surface to take part in the photocatalytic OER. The determination of the stable structures and electronic structures for $\mathrm{Ni}_{n}$, and $(\mathrm{NiO})_{n}$ adsorbed on the $\beta-\mathrm{Ga}_{2} \mathrm{O}_{3}$ surface provides a foundation for further investigations on the mechanism of the photocatalytic water-splitting reaction in the $\mathrm{NiO}_{x} / \mathrm{Ga}_{2} \mathrm{O}_{3}$ system as well as other $\mathrm{NiO}_{x} /$ semiconductor systems.

\section{Acknowledgements}

This work is financially supported by the National Natural Science Foundation of China under Grant 21473183 and 21361140346. We also appreciate the financial support by the National Basic Research Program of China (973 program 2014CB239400).

\section{References}

1 S. Y. Reece, J. A. Hamel, K. Sung, T. D. Jarvi, A. J. Esswein, J. J. H. Pijpers and D. G. Nocera, Science, 2011, 334, 645-648.

2 K. Maeda, K. Teramura, D. L. Lu, T. Takata, N. Saito, Y. Inoue and K. Domen, Nature, 2006, 440, 295.

3 A. Kudo and Y. Miseki, Chem. Soc. Rev., 2009, 38, 253-278.

4 X. Chen, S. Shen, L. Guo and S. S. Mao, Chem. Rev., 2010, 110, 6503-6570.

5 A. Fujishima and K. Honda, Nature, 1972, 238, 37-38.
6 J. Yang, D. Wang, H. Han and C. Li, Acc. Chem. Res., 2013, 46, 1900-1909.

7 X. Zong, H. J. Yan, G. P. Wu, G. J. Ma, F. Y. Wen, L. Wang and C. Li, J. Am. Chem. Soc., 2008, 130, 7176-7177.

8 H. Yan, J. Yang, G. Ma, G. Wu, X. Zong, Z. Lei, J. Shi and C. Li, J. Catal., 2009, 266, 165-168.

9 D. Y. C. Leung, X. L. Fu, C. F. Wang, M. Ni, M. K. H. Leung, X. X. Wang and X. Z. Fu, ChemSusChem, 2010, 3, 681-694.

10 D. Wang, R. Li, J. Zhu, J. Shi, J. Han, X. Zong and C. Li, J. Phys. Chem. C, 2012, 116, 5082-5089.

11 K. S. S. Ma, K. Maeda, R. Abe and K. Domen, Energy Environ. Sci., 2012, 5, 8390-8397.

12 M. Higashi, K. Domen and R. Abe, J. Am. Chem. Soc., 2012, 134, 6968-6971.

13 T. Yanagida, Y. Sakata and H. Imamura, Chem. Lett., 2004, 33, 726-727.

14 X. Wang, Q. Xu, M. Li, S. Shen, X. Wang, Y. Wang, Z. Feng, J. Shi, H. Han and C. Li, Angew. Chem., Int. Ed., 2012, 51, 13089-13092.

15 K. Domen, A. Kudo and T. Onishi, J. Catal., 1986, 102, 92-98. 16 K. Sayama and H. Arakawa, J. Photochem. Photobiol., A, 1994, 77, 243-247.

17 T. K. Townsend, N. D. Browning and F. E. Osterloh, Energy Environ. Sci., 2012, 5, 9543-9550.

18 H. Kato, K. Asakura and A. Kudo, J. Am. Chem. Soc., 2003, 125, 3082-3089.

19 A. Kudo, K. Sayama, A. Tanaka, K. Asakura, K. Domen, K. Maruya and T. Onishi, J. Catal., 1989, 120, 337-352.

20 Y. Miseki, H. Kato and A. Kudo, Chem. Lett., 2006, 35, 10521053.

21 K. Maeda, K. Teramura, D. Lu, N. Saito, Y. Inoue and K. Domen, Angew. Chem., Int. Ed., 2006, 45, 7806-7809.

22 D. Matthey, J. G. Wang, S. Wendt, J. Matthiesen, R. Schaub, E. Laegsgaard, B. Hammer and F. Besenbacher, Science, 2007, 315, 1692-1696.

23 H. G. Yang, C. H. Sun, S. Z. Qiao, J. Zou, G. Liu, S. C. Smith, H. M. Cheng and G. Q. Lu, Nature, 2008, 453, 638-641.

24 Y.-F. Li, Z.-P. Liu, L. L. Liu and W. Gao, J. Am. Chem. Soc., 2010, 132, 13008-13015.

25 M. Setvin, U. Aschauer, P. Scheiber, Y.-F. Li, W. Hou, M. Schmid, A. Selloni and U. Diebold, Science, 2013, 341, 988-991.

26 M. Zhang, J. Chen, Y. Yu and Y. Zhang, Appl. Surf. Sci., 2013, 287, 97-107.

27 C. D. Valentin, L. Giordano, G. Pacchioni and N. Rösch, Surf. Sci., 2003, 522, 175-184.

28 E. Escamilla-Roa, V. Timon and A. Hernandez-Laguna, Comput. Theor. Chem., 2012, 981, 59-67.

29 Y. Pan, C. Liu and Q. Ge, J. Catal., 2010, 272, 227-234.

30 J. Li, E. Croiset and L. Ricardez-Sandoval, J. Phys. Chem. C, 2013, 117, 16907-16920.

31 G. Kresse and J. Furthmüller, Phys. Rev. B: Condens. Matter Mater. Phys., 1996, 54, 11169.

32 G. Kresse and J. Furthmüller, Comput. Mater. Sci., 1996, 6, $15-50$.

33 J. P. Perdew, K. Burke and M. Ernzerhof, Phys. Rev. Lett., 1996, 77, 3865-3868. 
34 P. E. Blochl, Phys. Rev. B: Condens. Matter Mater. Phys., 1994, 50, 17953-17979.

35 G. Kresse and J. Joubert, Phys. Rev. B: Condens. Matter Mater. Phys., 1999, 59, 1758-1775.

36 S. L. Dudarev, G. A. Botton, S. Y. Savrasov, C. J. Humphreys and A. P. Sutton, Phys. Rev. B: Condens. Matter Mater. Phys., 1998, 57, 1505-1509.

37 A. M. Ferrari, C. Pisani, F. Cinquini, L. Giordano and G. Pacchioni, J. Chem. Phys., 2007, 127, 174711.

38 W. E. Pickett, S. C. Erwin and E. C. Ethridge, Phys. Rev. B: Condens. Matter Mater. Phys., 1998, 58, 1201-1209.

39 O. Bengone, M. Alouani, P. Blöchl and J. Hugel, Phys. Rev. B: Condens. Matter Mater. Phys., 2000, 62, 16392-16401.

40 R. Roy, V. G. Hill and E. F. Osborn, J. Am. Chem. Soc., 1952, 74, 719-722.

41 B. Zheng, W. Hua, Y. Yue and Z. Gao, J. Catal., 2005, 232, 143-151.

42 Y. Hou, L. Wu, X. Wang, Z. Ding, Z. Li and X. Fu, J. Catal., 2007, 250, 12-18.

43 H. He, R. Orlando, M. A. Blanco, R. Pandey, E. Amzallag, I. Baraille and M. Rérat, Phys. Rev. B: Condens. Matter Mater. Phys., 2006, 74, 195123.

44 S. Yoshioka, H. Hayashi, A. Kuwabara, F. Oba, K. Matsunaga and I. Tanaka, J. Phys.: Condens. Matter, 2007, 19, 346211.

45 Y. Sakata, Y. Matsuda, T. Yanagida, K. Hirata, H. Imamura and K. Teramura, Catal. Lett., 2008, 125, 22-26.

46 T. C. Lovejoy, E. N. Yitamben, N. Shamir, J. Morales, E. G. Villora, K. Shimamura, S. Zheng, F. S. Ohuchi and M. A. Olmstead, Appl. Phys. Lett., 2009, 94, 081906.
47 Y. Hou, J. Zhang, Z. Ding and L. Wu, Powder Technol., 2010, 203, 440-446.

48 Y. Sakata, Y. Matsuda, T. Nakagawa, R. Yasunaga, H. Imamura and K. Teramura, ChemSusChem, 2011, 4, 181-184.

49 T. Oshima, K. Kaminaga, H. Mashiko, A. Mukai, K. Sasak, T. Masui, A. Kuramata, S. Yamakoshi and A. Ohtomo, Jpn. J. Appl. Phys., 2013, 52, 111102.

50 S. Geller, J. Chem. Phys., 1960, 33, 676.

51 J. Heyd, G. E. Scuseria and M. Ernzerhof, J. Chem. Phys., 2003, 118, 8207-8215.

52 J. Heyd, G. E. Scuseria and M. Ernzerhof, J. Chem. Phys., 2004, 121, 1187-1192.

53 J. Heyd, G. E. Scuseria and M. Ernzerhof, J. Chem. Phys., 2006, 124, 219906.

54 H. H. Tippins, Phys. Rev. A, 1965, 140, A316-A319.

55 N. Ueda, H. Hosono, R. Waseda and H. Kawazoe, Appl. Phys. Lett., 1997, 71, 933-935.

56 V. M. Bermudez, Chem. Phys., 2006, 323, 193-203.

57 Y. Tomm, P. Reiche, D. Klimm and T. Fukuda, J. Cryst. Growth, 2000, 220, 510-514.

58 E. G. Villora, Y. Murakami, T. Sugawara, T. Atou, M. Kikuchi, D. Shindo and T. Fukuda, Mater. Res. Bull., 2002, 37, 769774.

59 R. F. W. Bader, Chem. Rev., 1991, 91, 893-928.

60 W. Tang, E. Sanville and G. Henkelman, J. Phys.: Condens. Matter, 2009, 21, 084204. 